\title{
Communication
}

\section{Force-Dependent Multicolor Mechanochromism from a Single Mechanophore}

\author{
Molly E. McFadden, and Maxwell J. Robb
}

J. Am. Chem. Soc., Just Accepted Manuscript • DOI: 10.1021/jacs.9b05280 • Publication Date (Web): 08 Jul 2019

Downloaded from http://pubs.acs.org on July 8, 2019

\section{Just Accepted}

"Just Accepted" manuscripts have been peer-reviewed and accepted for publication. They are posted online prior to technical editing, formatting for publication and author proofing. The American Chemical Society provides "Just Accepted" as a service to the research community to expedite the dissemination of scientific material as soon as possible after acceptance. "Just Accepted" manuscripts appear in full in PDF format accompanied by an HTML abstract. "Just Accepted" manuscripts have been fully peer reviewed, but should not be considered the official version of record. They are citable by the Digital Object Identifier (DOI®). "Just Accepted" is an optional service offered to authors. Therefore, the "Just Accepted" Web site may not include all articles that will be published in the journal. After a manuscript is technically edited and formatted, it will be removed from the "Just Accepted" Web site and published as an ASAP article. Note that technical editing may introduce minor changes to the manuscript text and/or graphics which could affect content, and all legal disclaimers and ethical guidelines that apply to the journal pertain. ACS cannot be held responsible for errors or consequences arising from the use of information contained in these "Just Accepted" manuscripts. 
Mechanophores are molecules that undergo specific and productive chemical transformations under mechanical stress. ${ }^{1}$ In polymer mechanochemistry, force is transduced to a mechanophore through covalently linked polymer chains. ${ }^{2}$ Mechanophores that exhibit changes in color or luminescence, for example, enable the straightforward visible detection of stress and/or strain in polymers and polymeric materials. ${ }^{3}$ A diverse library of mechanochromic molecular force probes has emerged including spiropyran $^{4}$ and naphthopyran, ${ }^{5}$ which undergo $6 \pi$ electrocyclic ringopening reactions under force to generate colored merocyanine dyes. In addition, mechanophores that homolytically cleave to generate colored radical species,${ }^{6}$ the force-activated unzipping of polyladderene to form conjugated polyacetylene, ${ }^{7}$ and the ringopening reaction of rhodamine ${ }^{8}$ have also been recently reported.

The development of mechanochromic mechanophores that are capable of distinguishing between different magnitudes of force through discrete visual signals remains an important challenge. Spiropyran $^{4 \mathrm{~d}, 9}$ and rhodamine ${ }^{8 \mathrm{~b}}$ exhibit a unique color transition in materials under active stress and after relaxation due to presumed changes in cis-trans isomerization and conformational torsion, respectively. Furthermore, taking advantage of the unique properties of phase-separated polymer and composite materials, differential activation of two different mechanochromic mechanophores introduced into hard and soft domains has been demonstrated under varying degrees of mechanical stimulation. ${ }^{10}$ A single mechanophore, however, that is capable of achieving a forcedependent, gradient multicolor response is a desirable target.

We were intrigued by reports of multicolor photochromism in bis-naphthopyran (BNP) chromophores (Scheme 1). ${ }^{11}$ The two pyran rings, which are initially in the closed-closed state $\left(\mathrm{BNP}_{\mathrm{C}-\mathrm{C}}\right)$, open sequentially under extended irradiation with UV light to generate distinctly colored merocyanine dyes. A single ring-opening reaction produces the open-closed form $\left(\mathrm{BNP}_{\mathrm{O}-\mathrm{C}}\right)$

Scheme 1. Electrocyclic reactions of bis-naphthopyran produce distinctly colored merocyanine products via photochemical, thermal, and mechanochemical processes.

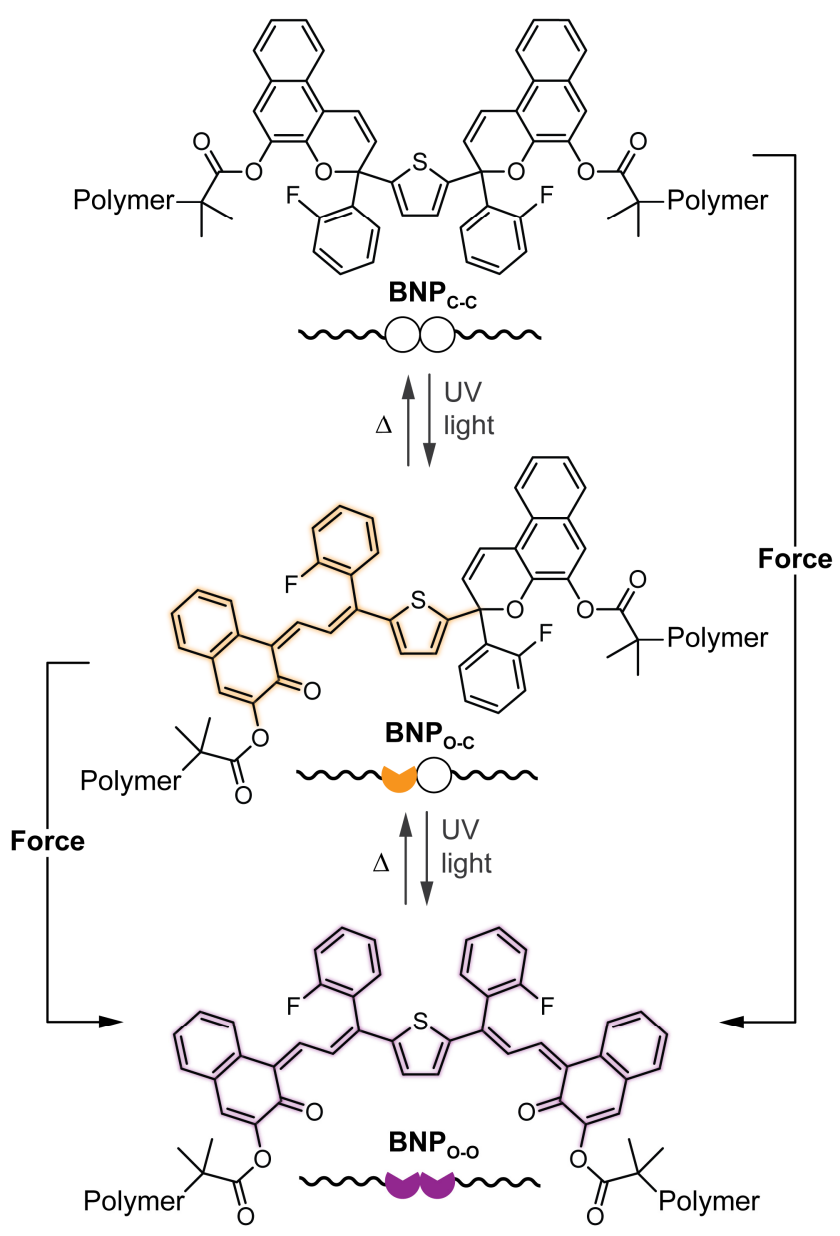

with absorption properties characteristic of typical merocyanine dyes; however, the ring-opening reaction of the second pyran unit generates the open-open bis-merocyanine species $\left(\mathrm{BNP}_{\mathrm{O}-\mathrm{O}}\right)$ that absorbs at longer wavelengths due to conjugation through the thiophene linker. Here, we report the mechanochemical reactivity of a BNP mechanophore that exhibits force-dependent multicolor mechanochromism. Interestingly, the mechanochemical behavior of the BNP mechanophore is distinct from its photochemical reactivity. In contrast to the sequential ring-opening behavior with light, BNPo-o appears to be generated directly with force. A dy- 
namic equilibrium is achieved under mechanical activation in which the distribution of merocyanine products is increasingly biased toward BNPo-o with greater force applied to the BNP mechanophore. The trend in mechanochemical reactivity is described by a mechanistic model that captures the experimentally determined force-color relationship.

Density functional theory (DFT) calculations using the easily implemented constrained geometries simulate external force (CoGEF) method $^{12}$ were initially performed to evaluate the mechanochemical activity of bis-naphthopyran (see the Supporting Information (SI) for details). Encouragingly, the calculations predict successful ring-opening reactions of both pyran units upon molecular elongation. To experimentally evaluate the mechanochemical reactivity of bis-naphthopyran, we synthesized a series of poly(methyl acrylate) (PMA) polymers incorporating a BNP unit near the center of the polymer chain (Scheme 2). An ortho-

Scheme 2. Synthesis of poly(methyl acrylate) polymers containing a chain-centered bis-naphthopyran unit.

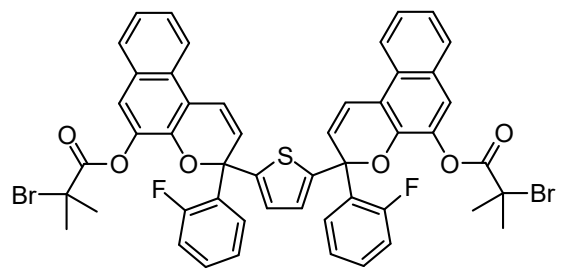

these conditions is dependent upon the length of the chain. ${ }^{14}$ Thus, the magnitude of force applied to a BNP molecule during ultrasonication is tuned by varying the degree of polymerization (DP) of the attached polymer chains, with longer polymers transducing greater force. Accordingly, the activation rate of mechanochemical reactions is directly proportional to DP above a threshold chain length. ${ }^{12 b}$ Although DP is a better descriptor of mechanical activation, ${ }^{15}$ we refer to polymer molecular weight as a more identifiable metric since only PMA was used in this study.

The photochromic properties of a $330 \mathrm{kDa}$ polymer containing a chain-centered bis-naphthopyran molecule (BNP-PMA330) were initially investigated and compared to its mechanochemical reactivity. Photochemical and mechanochemical reactions were monitored in real-time by UV-vis absorption spectroscopy using a peristaltic pump to continuously circulate a polymer solution between a reaction vessel and a UV-vis flow cell. ${ }^{15 a}$ A THF solution of BNP-PMA $\mathbf{A 3}_{30}$ at $-45^{\circ} \mathrm{C}$ was irradiated with UV light $(\lambda=311$ $\mathrm{nm}$ ) and absorption spectra were acquired over time (Figure 1a). At early irradiation times, a new peak with an absorption maximum at approximately $460 \mathrm{~nm}$ emerges, corresponding to the BNPO-C species. ${ }^{11 a}$ A longer wavelength absorption signal appears after extended UV irradiation that corresponds to the BNPO-O form. To better characterize the formation of each species over time, the absorbance at two characteristic wavelengths of $460 \mathrm{~nm}$ and $620 \mathrm{~nm}$ were monitored continuously. The latter wavelength was chosen to minimize overlap with the absorption of $\mathrm{BNP}_{\mathrm{O}-\mathrm{C}}$, allowing for the selective detection of BNPo-o. Under constant photoirradiation of BNP-PMA330, the absorbance at $460 \mathrm{~nm}$ increases rapidly and reaches a maximum well before the absorbance at $620 \mathrm{~nm}$. These observations are consistent with a sequential photoactivation mechanism in which $\mathrm{BNP}_{\mathrm{C}-\mathrm{C}}$ undergoes a single ring-opening reaction to generate $\mathrm{BNP}_{\mathrm{O}-\mathrm{C}}$, followed by transformation of the second pyran ring to produce $\mathrm{BNP}_{\mathrm{O}-\mathrm{O} \text {. }}$ Tracking the concentration of each species as a function of photoirradiation time using extinction coefficients estimated from similar isolated small molecules ${ }^{11 \mathrm{a}, \mathrm{b}}$ further supports this mechanism (Figure S1).

Mechanochemical activation of PMA chain-centered bisnaphthopyran was investigated by subjecting polymers in THF at $-45{ }^{\circ} \mathrm{C}$ to continuous ultrasonication $\left(8.2 \mathrm{~W} / \mathrm{cm}^{2}\right)$ using the same analytical flow setup employed in the photoirradiation experiments. In contrast to the sequential photoactivation behavior, mechanochemical activation of BNP-PMA330 occurs via a different mechanism (Figure 1b). The absorbance at $620 \mathrm{~nm}$ reaches a maximum value early, while the absorbance at $460 \mathrm{~nm}$ continues to increase more slowly with longer ultrasonication exposure. These data indicate that $\mathrm{BNP}_{\mathrm{O}-\mathrm{O}}$ is formed relatively quickly in the mechanochemical reaction compared to $\mathrm{BNP}_{\mathrm{O}-\mathrm{C}}$, which is generated relatively slowly. Ultrasound-induced mechanical activation of lower molecular weight BNP-PMA40 under the same conditions exhibits a similar trend in absorbance over time with the population of $\mathrm{BNP}_{\mathrm{O}-\mathrm{O}}$ reaching a steady state before $\mathrm{BNP}_{\mathrm{O}-\mathrm{C}}$; however, the absorption spectra are markedly different (Figure 1c). Remarkably, these results suggest that the relative distribution of $\mathrm{BNP}_{\mathrm{O}-\mathrm{C}}$ and $\mathrm{BNP}_{\mathrm{O}-\mathrm{O}}$ resulting from the mechanochemical reaction and the correlated visible absorption spectrum are forcedependent (vide infra). Control experiments performed on a chain-end functional polymer confirm the mechanical origin of the observed ultrasound-induced reactivity (Figure S2).

To further quantify how varying force affects the dynamic equilibrium of the system and the distribution of merocyanine species at the mechanostationary state, ${ }^{15 a}$ the series of polymers was subjected to ultrasound-induced mechanical activation as described above, the absorbance at $460 \mathrm{~nm}$ and $620 \mathrm{~nm}$ was plotted as a function of sonication time, and the curves were fitted to eq 1 :

$$
\operatorname{Abs}(t)=B\left(1-e^{-k t}\right)
$$


(a) Photochemical (330 kDa) the force-color relationship.

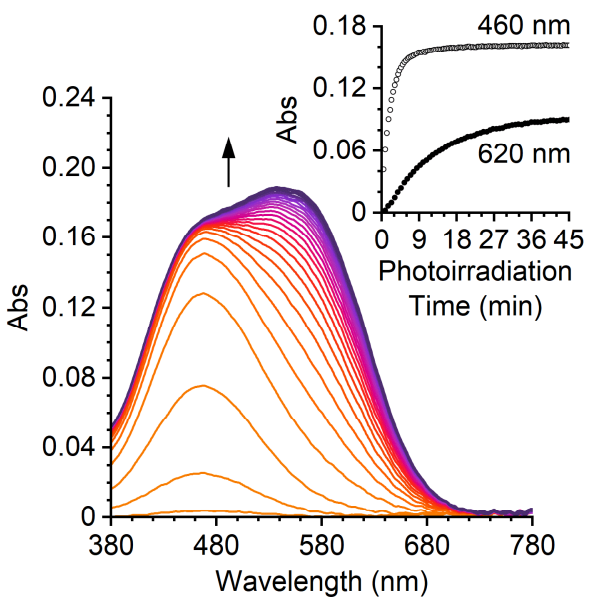

(b) Mechanochemical (330 kDa)

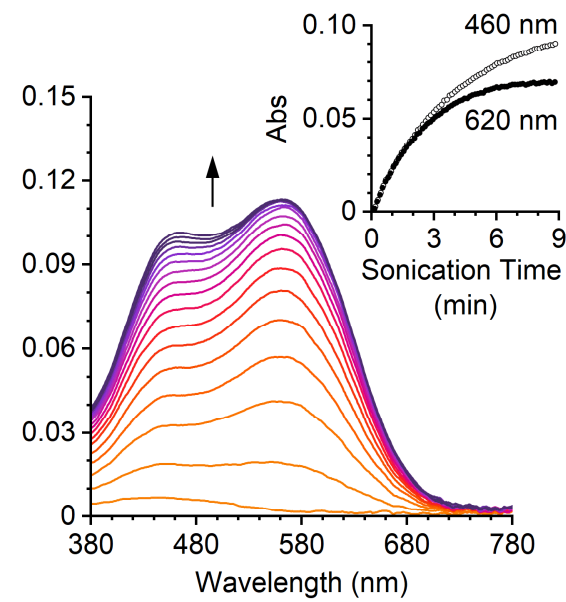

(c) Mechanochemical (40 kDa)

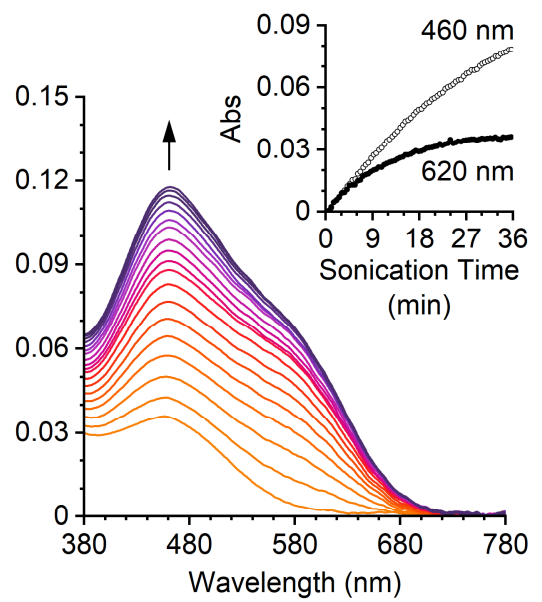

Figure 1. UV-vis absorption behavior of bis-naphthopyran under photochemical and mechanochemical activation. (a) Absorption spectra of $330 \mathrm{kDa}$ BNP-PMA330 upon increasing exposure to UV light $(\lambda=311 \mathrm{~nm})$ illustrating sequential ring-opening behavior. Insets show absorbance monitored at characteristic wavelengths of $460 \mathrm{~nm}$ and $620 \mathrm{~nm}$ during the reactions. UV-vis absorption behavior of (b) 330 kDa BNP-PMA330 and (c) 40 kDa BNP-PMA40 subjected to ultrasound-induced mechanochemical activation demonstrating a nonsequential ring-opening process and force-dependent visible absorption. Polymer concentrations are $2 \mathrm{mg} / \mathrm{mL}$ in THF.

where $A b s(t)$ is the absorbance at a specific wavelength at time $t$, $B$ is the amplitude (the maximum absorbance value), and $k$ is the effective rate constant. A representative example is illustrated in Figure 2a. Average values of $B$ measured at $460 \mathrm{~nm}\left(B_{460}\right)$ and $620 \mathrm{~nm}\left(B_{620}\right)$ were determined from a minimum of three trials for each polymer and are reflective of the steady-state concentration of merocyanine species. More importantly, as discussed below, the ratio of $B_{620}$ to $B_{460}$ for each polymer provides a consistent measure of the ensemble average steady-state distribution of $\mathrm{BNP}_{\mathrm{O}-\mathrm{C}}$ and $\mathrm{BNP}_{\mathrm{O}-\mathrm{O}}$ at a particular applied force (Table 1).

Representative traces of absorbance at $620 \mathrm{~nm}$ scaled to respective values of $B_{460}$ as a function of sonication time are shown for each polymer in Figure $2 b$. These data reveal how the populations of merocyanine species change over time to reach a steady-state concentration of $\mathrm{BNP}_{\mathrm{O}-\mathrm{C}}$ and $\mathrm{BNP}_{\mathrm{O}-\mathrm{O}}$. The relative spectral contribution from the $\mathrm{BNP}_{\mathrm{O}-\mathrm{o}}$ state becomes greater with increasing molecular weight of the attached polymers, and thus with greater force applied to the BNP mechanophore. Additionally, the steadystate concentration of $\mathrm{BNP}_{\mathrm{O}-\mathrm{O}}$ is reached faster with higher molecular weight polymers, which is consistent with longer chains being activated more quickly in mechanochemical reactions.
We constructed a theoretical model to further understand the force-color relationship observed for the BNP mechanophore (Figure 2c). As mentioned above, the average ratio of $B_{620} / B_{460}$ determined for each polymer serves as a proxy to describe the overall distribution of $\mathrm{BNP}_{\mathrm{O}-\mathrm{C}}$ and $\mathrm{BNP}_{\mathrm{O}-\mathrm{O}}$ resulting from the mechanochemical reaction. In the model, the relative steady-state concentrations $(\varphi)$ of $\mathrm{BNP}_{\mathrm{O}-\mathrm{C}}$ and $\mathrm{BNP} \mathrm{O}_{\mathrm{o}}$ given by eq 2 :

$$
\varphi_{\mathrm{O}-\mathrm{O}}=1-\varphi_{\mathrm{O}-\mathrm{C}}=\frac{\left[\mathrm{BNP}_{\mathrm{O}-\mathrm{O}}\right]}{\left[\mathrm{BNP}_{\mathrm{O}-\mathrm{C}}\right]+\left[\mathrm{BNP}_{\mathrm{O}-\mathrm{O}}\right]}
$$

are related to $M_{\mathrm{n}}$ according to eq 3 :

$$
\varphi_{\mathrm{O}-\mathrm{O}}=1-e^{-c\left(M_{\mathrm{n}} / M_{0}\right)}
$$

where $c$ is a constant and $M_{0}$ is the molecular weight of the monomer unit ( $\left.\mathrm{DP}=M_{\mathrm{n}} / M_{0}\right)$. The concentration of each merocyanine species can be calculated from the experimentally determined absorbance values at $460 \mathrm{~nm}$ and $620 \mathrm{~nm}$ using the Beer-Lambert relationship and previously estimated extinction coefficients to predict the dependence of $B_{620} / B_{460}$ on $M_{\mathrm{n}}$ (see the SI for details). The goal of this model is not to describe the system exactly, but rather capture the overall trend observed for the changes in visible absorption resulting from mechanical activation of BNP with
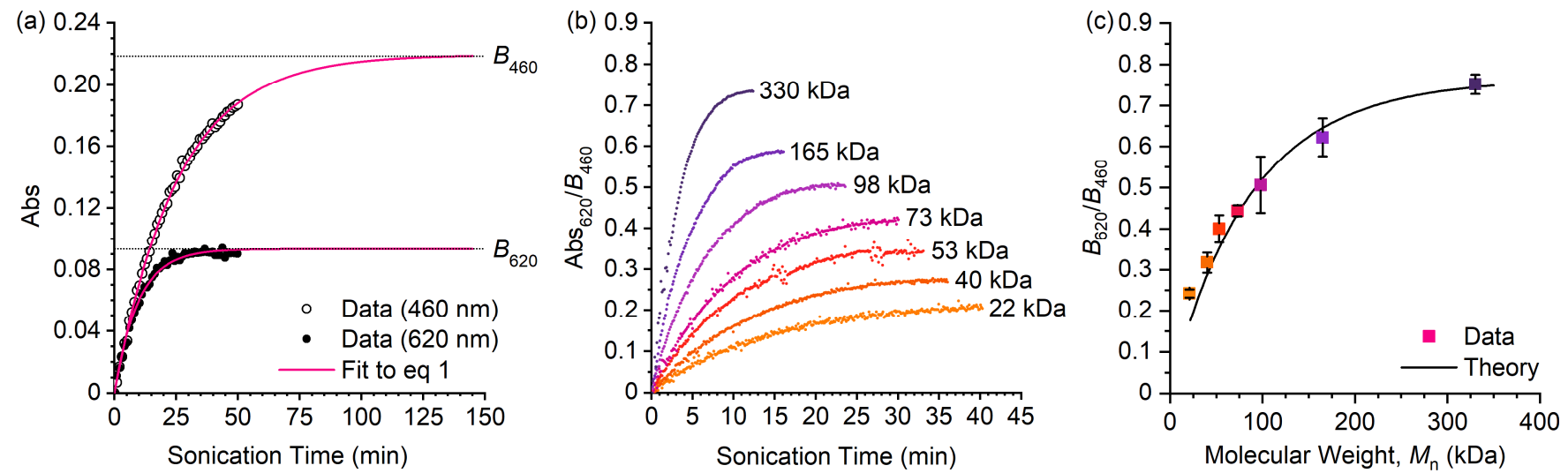

Figure 2. Evaluation of force-dependent mechanochromism of the BNP mechanophore. (a) Representative kinetic plots for BNP-PMA73 demonstrating the determination of steady-state absorbance values. Absorbance at $460 \mathrm{~nm}$ and $620 \mathrm{~nm}$ was recorded for each polymer during ultrasound-induced mechanical activation and fitted to eq 1 to calculate $B_{460}$ and $B_{620}$. (b) Representative traces of absorbance at $620 \mathrm{~nm}$ as a function of sonication time for each polymer scaled to their respective values of $B_{460}$. (c) Ratios of $B_{620} / B_{460}$ determined for polymers of varying $M_{\mathrm{n}}$ describe the overall distribution of $\mathrm{BNP}_{\mathrm{O}-\mathrm{C}}$ and $\mathrm{BNP}_{\mathrm{O}-\mathrm{O}}$ and are consistent with a theoretical model that predicts 
varying force. This simple model is in good agreement with the data.

The experimental results presented above demonstrating forcedependent, gradient multicolor mechanochromism of the BNP mechanophore are consistent with a non-sequential activation mechanism in which $\mathrm{BNP}_{\mathrm{C}-\mathrm{C}}$ is converted directly to BNPo-o (see

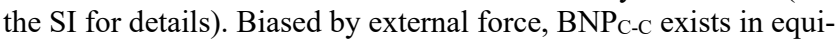
librium with BNPo-c and BNPo-o and the distribution of the two merocyanine species is dictated by the balance between the forward rate of mechanochemical activation and thermal electrocyclization, resulting in a mechanostationary state. Although the complex interconversion processes preclude an exact solution of the rate law, numerical modeling supports the proposed mechanism and suggests that $\mathrm{BNP}_{\mathrm{O}-\mathrm{C}}$ is produced predominately, if not exclusively, from thermal electrocyclization of BNPo-o. The data and the kinetic model also indicate that $\mathrm{BNP}_{\mathrm{O}-\mathrm{c}}$ can be activated mechanochemically to regenerate $\mathrm{BNP}$ o-o. As the average DP, or $M_{\mathrm{n}}$, of the polymers attached to the BNP mechanophore increases, the rate of electrocyclic ring-opening increases, which shifts the merocyanine distribution at the mechanostationary state toward BNPo-o. This feature is reflected in a greater spectral contribution from BNPo-o relative to BNPO-C and a larger ratio of $B_{620} / B_{460}$. This mechanism also accounts for the more rapid mechanochemical generation of BNPo-o compared to BNPo-c. With the exception of BNP-PMA22, polymer chain scission occurs with extended ultrasonication as expected, leading to irreversible loss of $\mathrm{BNP}_{\mathrm{O}-\mathrm{O}}$. This degradation pathway is included explicitly in the kinetic model; however, it appears to have a minimal effect on the value of $B_{620} / B_{460}$.

In summary, we have developed a bis-naphthopyran (BNP) mechanophore that exhibits force-dependent, gradient multicolor mechanochromism. The BNP mechanophore was incorporated into a series of polymers with different degrees of polymerization and mechanically activated in solution using ultrasonication. By changing the length of the attached polymer chains, the amount of force delivered to the mechanophore was varied systematically. Mechanical activation of BNP proceeds via a mechanistically distinct pathway compared to the photochemical process. Increasing the force applied to the BNP mechanophore predictably alters the relative distribution of two distinctly colored merocyanine products, resulting in a graded change in the overall visible absorption spectrum. The mechanochemical behavior of the BNP mechanophore is described by a theoretical model that provides insight into the force-color relationship.

\section{ASSOCIATED CONTENT}

\section{Supporting Information}

The Supporting Information is available free of charge on the ACS Publications website.

Experimental details and additional characterization data, kinetic modeling, synthetic procedures, DFT calculations, GPC chromatograms, UV-vis data, and NMR spectra (PDF).

\section{AUTHOR INFORMATION}

\section{Corresponding Author}

mrobb@caltech.edu

\section{Notes}

The authors declare no competing financial interests.

\section{ACKNOWLEDGMENT}

Financial support from Caltech and the Dow Next Generation Educator Fund is gratefully acknowledged. We thank Corey Husic, Anna Overholts, and Dr. Scott Virgil for helpful discus- sions and the Caltech Center for Catalysis and Chemical Synthesis of the Beckman Institute at Caltech for access to equipment. MEM was supported by a NSF Graduate Research Fellowship (DGE-1745301).

\section{REFERENCES}

(1) Li, J.; Nagamani, C.; Moore, J. S. Polymer Mechanochemistry: From Destructive to Productive. Acc. Chem. Res. 2015, 48, 2181-2190.

(2) (a) Beyer, M. K.; Clausen-Schaumann, H. Mechanochemistry: The Mechanical Activation of Covalent Bonds. Chem. Rev. 2005, 105, 29212948. (b) Caruso, M. M.; Davis, D. A.; Shen, Q.; Odom, S. A.; Sottos, N. R.; White, S. R.; Moore, J. S. Mechanically-Induced Chemical Changes in Polymeric Materials. Chem. Rev. 2009, 109, 5755-5798.

(3) (a) Chen, Y.; Spiering, A. J. H.; Karthikeyan, S.; Peters, G. W. M.; Meijer, E. W.; Sijbesma, R. P. Mechanically Induced Chemiluminescence from Polymers Incorporating a 1,2-Dioxetane Unit in the Main Chain. Nat. Chem. 2012, 4, 559-562. (b) Zhang, H.; Gao, F.; Cao, X.; Li, Y.; Xu, Y.; Weng, W.; Boulatov, R. Mechanochromism and Mechanical-ForceTriggered Cross-Linking from a Single Reactive Moiety Incorporated into Polymer Chains. Angew. Chem. Int. Ed. 2016, 55, 3040-3044. (c) Li, Z.; Toivola, R.; Ding, F.; Yang, J.; Lai, P.-N.; Howie, T.; Georgeson, G.; Jang, S.-H.; Li, X.; Flinn, B. D.; Jen, A. K.-Y. Highly Sensitive Built-In Strain Sensors for Polymer Composites: Fluorescence Turn-On Response through Mechanochemical Activation. Adv. Mater. 2016, 28, 6592-6597. (d) Clough, J. M.; Creton, C.; Craig, S. L.; Sijbesma, R. P. Covalent Bond Scission in the Mullins Effect of a Filled Elastomer: Real-Time Visualization with Mechanoluminescence. Adv. Funct. Mater. 2016, 26, 9063-9074. (e) Göstl, R.; Sijbesma, R. P. $\pi$-Extended Anthracenes as Sensitive Probes for Mechanical Stress. Chem. Sci. 2016, 7, 370-375. (f) Sagara, Y.; Karman, M.; Verde-Sesto, E.; Matsuo, K.; Kim, Y.; Tamaoki, N.; Weder, C. Rotaxanes as Mechanochromic Fluorescent Force Transducers in Polymers. J. Am. Chem. Soc. 2018, 140, 1584-1587. (g) Sagara, Y.; Karman, M.; Seki, A.; Pannipara, M.; Tamaoki, N.; Weder, C. Rotaxane-Based Mechanophores Enable Polymers with Mechanically Switchable White Photoluminescence. ACS Cent. Sci. 2019, 5, 874-881.

(4) (a) Potisek, S. L.; Davis, D. A.; Sottos, N. R.; White, S. R.; Moore, J. S. Mechanophore-Linked Addition Polymers. J. Am. Chem. Soc. 2007, 129, 13808-13809. (b) Davis, D. A.; Hamilton, A.; Yang, J.; Cremar, L. D.; Van Gough, D.; Potisek, S. L.; Ong, M. T.; Braun, P. V.; Martínez, T. J.; White, S. R.; Moore, J. S.; Sottos, N. R. Force-Induced Activation of Covalent Bonds in Mechanoresponsive Polymeric Materials. Nature 2009, 459, 68-72. (c) Lee, C. K.; Beiermann, B. A.; Silberstein, M. N.; Wang, J.; Moore, J. S.; Sottos, N. R.; Braun, P. V. Exploiting Force Sensitive Spiropyrans as Molecular Level Probes. Macromolecules 2013, 46, 3746 3752. (d) Gossweiler, G. R.; Hewage, G. B.; Soriano, G.; Wang, Q.; Welshofer, G. W.; Zhao, X.; Craig, S. L. Mechanochemical Activation of Covalent Bonds in Polymers with Full and Repeatable Macroscopic Shape Recovery. ACS Macro Lett. 2014, 3, 216-219. (e) Zhang, H.; Chen, Y.; Lin, Y.; Fang, X.; Xu, Y.; Ruan, Y.; Weng, W. Spiropyran as a Mechanochromic Probe in Dual Cross-Linked Elastomers. Macromolecules 2014, 47, 6783-6790. (f) Peterson, G. I.; Larsen, M. B.; Ganter, M. A.; Storti, D. W.; Boydston, A. J. 3D-Printed Mechanochromic Materials. ACS Appl. Mater. Interfaces 2015, 7, 577-583. (g) Gossweiler, G. R.; Kouznetsova, T. B.; Craig, S. L. Force-Rate Characterization of Two Spiropyran-Based Molecular Force Probes. J. Am. Chem. Soc. 2015, 137, 6148-6151. (f) Lin, Y.; Barbee, M. H.; Chang, C. C.; Craig, S. L. Regiochemical Effects on Mechanophore Activation in Bulk Materials. $J$. Am. Chem. Soc. 2018, 140, 15969-15975.

(5) Robb, M. J.; Kim, T. A.; Halmes, A. J.; White, S. R.; Sottos, N. R.; Moore, J. S. Regioisomer-Specific Mechanochromism of Naphthopyran in Polymeric Materials. J. Am. Chem. Soc. 2016, 138, 12328-12331.

(6) (a) Imato, K.; Irie, A.; Kosuge, T.; Ohishi, T.; Nishihara, M.; Takahara, A.; Otsuka, H. Mechanophores with a Reversible Radical System and Freezing-Induced Mechanochemistry in Polymer Solutions and Gels. Angew. Chem. Int. Ed. 2015, 54, 6168-6172. (b) Verstraeten, F.; Göstl, R.; Sijbesma, R. P. Stress-Induced Colouration and Crosslinking of Polymeric Materials by Mechanochemical Formation of Triphenylimidazolyl Radicals. Chem. Commun. 2016, 52, 8608-8611. (c) Ishizuki, K.; Oka, H.; Aoki, D.; Goseki, R.; Otsuka, H. Mechanochromic Polymers That Turn Green Upon the Dissociation of Diarylbibenzothiophenonyl: The Missing Piece toward Rainbow Mechanochromism. Chem. Eur. J. 2018, 24, 3170-3173. (d) Sakai, H.; Sumi, T.; Aoki, D.; Goseki, R.; Otsuka, H. Thermally Stable Radical-Type Mechanochromic Polymers Based on Difluorenylsuccinonitrile. ACS Macro Lett. 2018, 7, 1359-1363. 
(7) Chen, Z.; Mercer, J. A. M.; Zhu, X.; Romaniuk, J. A. H.; Pfattner, R.; Cegelski, L.; Martinez, T. J.; Burns, N. Z.; Xia, Y. Mechanochemical Unzipping of Insulating Polyladderene to Semiconducting Polyacetylene. Science. 2017, 357, 475-479.

(8) (a) Wang, Z.; Ma, Z.; Wang, Y.; Xu, Z.; Luo, Y.; Wei, Y.; Jia, X. A Novel Mechanochromic and Photochromic Polymer Film: When Rhodamine Joins Polyurethane. Adv. Mater. 2015, 27, 6469-6474. (b) Wang, T.; Zhang, N.; Dai, J.; Li, Z.; Bai, W.; Bai, R. Novel Reversible Mechanochromic Elastomer with High Sensitivity: Bond Scission and Bending-Induced Multicolor Switching. ACS Appl. Mater. Interfaces 2017, 9, 11874-11881.

(9) Kim, T. A.; Robb, M. J.; Moore, J. S.; White, S. R.; Sottos, N. R. Mechanical Reactivity of Two Different Spiropyran Mechanophores in Polydimethylsiloxane. Macromolecules 2018, 51, 9177-9183.

(10) (a) Ishizuki, K.; Aoki, D.; Goseki, R.; Otsuka, H. Multicolor Mechanochromic Polymer Blends That Can Discriminate between Stretching and Grinding. ACS Macro Lett. 2018, 7, 556-560. (b) Kosuge, T.; Zhu, X.; Lau, V. M.; Aoki, D.; Martinez, T. J.; Moore, J. S.; Otsuka, H. Multicolor Mechanochromism of a Polymer/Silica Composite with Dual Distinct Mechanophores. J. Am. Chem. Soc. 2019, 141, 1898-1902.

(11) (a) Lu, X.; Dong, Q.; Dong, X.; Zhao, W. Synthesis and Sequential Photochromism of Thiophene-Linked Bis-Pyrans. Tetrahedron 2015, 71, 4061-4069. (b) Zhao, W.; Carreira, E. M. Oligothiophene-Linked Bisnaphthopyrans: Sequential and Temperature-Dependent Photochromism. Chem. Eur. J. 2007, 13, 2671-2688. (c) Zhao, W.; Carreira, E. M. A Smart Photochromophore through Synergistic Coupling of Photochromic Subunits. J. Am. Chem. Soc. 2002, 124, 1582-1583.

(12) (a) Beyer, M. K. The Mechanical Strength of a Covalent Bond Calculated by Density Functional Theory. J. Chem. Phys. 2000, 112, 7307-7312. (b) Kryger, M. J.; Munaretto, A. M.; Moore, J. S. StructureMechanochemical Activity Relationships for Cyclobutane Mechanophores. J. Am. Chem. Soc. 2011, 133, 18992-18998.

(13) Gabbutt, C. D.; Heron, B. M.; Instone, A. C. Control of the Fading Properties of Photochromic 3,3-Diaryl-3H-Naphtho[2,1-b]Pyrans. Heterocycles 2003, 60, 843-855.

(14) Odell, J. A.; Keller, A. Flow-Induced Chain Fracture of Isolated Linear Macromolecules in Solution. J. Polym. Sci., Part B: Polym. Phys. 1986, 24, 1889-1916.

(15) (a) May, P. A.; Munaretto, N. F.; Hamoy, M. B.; Robb, M. J.; Moore, J. S. Is Molecular Weight or Degree of Polymerization a Better Descriptor of Ultrasound-Induced Mechanochemical Transduction? ACS Macro Lett. 2016, 5, 177-180. (b) Schaefer, M.; Icli, B.; Weder, C.; Lattuada, M.; Kilbinger, A. F. M.; Simon, Y. C. The Role of Mass and Length in the Sonochemistry of Polymers. Macromolecules 2016, 49, $1630-1636$. 
Insert Table of Contents artwork here

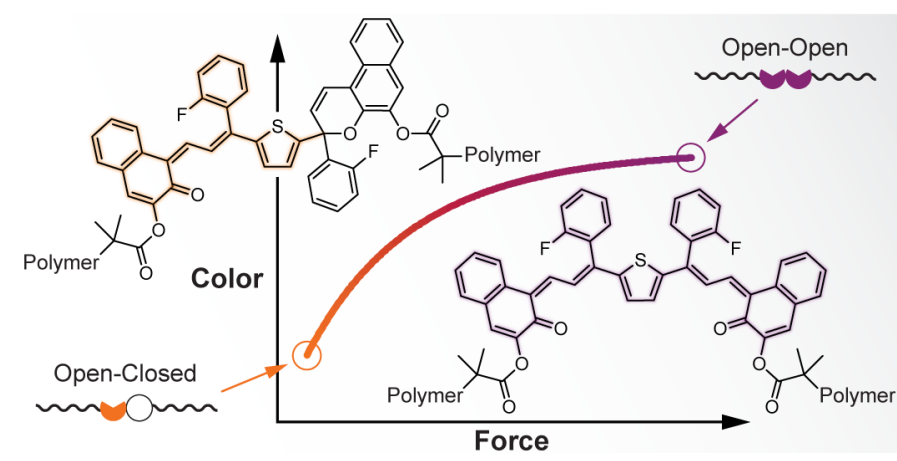

